
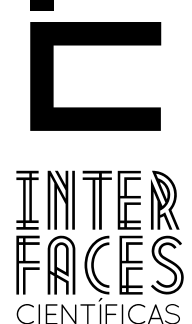

EDUCAÇÃO

\title{
LUZ, CÂMERA E EDUCAÇ̄̃̃: A PEDAGOGIA DO CINEMA NA FORMAÇÃO DE PROFESSORES
}

Albano Goes Souza ${ }^{1}$

Ronaldo Nunes Linhares
Edson Victor Lima Mendonça²

\section{RESUMO}

Pensar o cinema enquanto prática pedagógica é elucidar a complexidade do processo de educação, de como o olhar pode ser direcionado para esse foco, bem como questões culturais que envolvem este processo. A partir disso, o presente artigo tem por objetivo estudar a utilização de filmes no processo de formação docente inicial das licenciaturas em História, Geografia, Educação Física, Matemática, Biologia, Letras-Português, Letras-Inglês e Informática da Universidade Tiradentes (UNIT). É utilizado como método norteador a pesquisa social descritiva, voltada para análise e interpretação, tanto dos dados obtidos quanto dos resultados alcança- dos. Esse artigo é análise do projeto intitulado "Filmes sobre Professor: análise da utilização e contribuição para identidade de professores sergipanos em formação", desenvolvido no Grupo de Estudos Comunicação, Educação e Sociedade (GECES/CNPQ) com o apoio financeiro da Fundação de Apoio à Pesquisa e Inovação Tecnológica do Estado de Sergipe (FAPITEC-SE).

\section{PALAVRAS-CHAVE}

Educação. Formação de Professores. Cinema. 


\section{ABSTRACT}

Thinking the cinema as a pedagogical practice is elucidating the complexity of the education process, the look which can be directed toward this focus, and the cultural issues that surround this process as well. Taking it as a starting point, this paper aims to investigate the use of films in the process of initial teacher training in History, Geography, Physical Education, Mathematics, Biology, Portuguese, English, and Informatics degrees of the Tiradentes University (UNIT). It is used as a guiding method of the social descriptive research, focusing the analysis and interpretation of both data and outcomes. This article represents the analysis of the project entitled "Films about Professors: analysis of the use and contribution to the identity of teachers from Sergipe in a formation process," developed by the Group of Communication Studies, Education and Society (GECES / CNPq) with the financial support from the Foundation for Support of research and Technological Innovation of the State of Sergipe (SE-FAPITEC).

\section{KEY WORDS}

Education. Teacher's Formation. Cinema.

\section{RESUMEN}

Pensar en la película como práctica pedagógica es dilucidar la complejidad del proceso de educación y la forma en que la mirada puede dirigirse a este enfoque, así como los aspectos culturales que están involucrados en este proceso. A partir de esto, este trabajo tiene como objetivo investigar el uso de películas en el proceso de formación docente para grados iniciales en Historia, Geografía, Educación Física, Matemáticas, Biología, Lengua Portuguesa, Lengua Inglesa e Informática de la, Universidad Tiradentes (UNIT). Se utiliza como método guía la investigación social descriptiva, centrada en el análisis y la interpretación de los datos y los resultados. Este artículo es el análisis del proyecto titulado "Las películas sobre el profesor: análisis de la utilización y la contribución a la identidad de la formación de profesores en Sergipe", desarrollado por el Grupo de Estudios sobre Comunicación, Educación y Sociedad (GECES / CNPq), con el apoyo financiero de la Fundación de Apoyo a la Investigación e Innovación Tecnológica del Estado de Sergipe (SE-FAPITEC).

\section{PALABRAS CLAVE}

Educación. Formación de Docentes. Cine.

\section{INTRODUÇ̄̃̃O}

Na contemporaneidade, a discussão sobre o papel da educação em uma sociedade onde as relações sociais são realizadas a partir de contextos diversificados, permite-nos debruçar sobre a maneira como são formados nossos professores e quais elementos são necessários serem incluídos nesse processo para que, ao concluir sua graduação, o futuro professor tenha condições de incorporar em sua prática educativa os elementos constituídos para uma determinada sociedade. Apesar disso, percebemos que algumas universidades costumam distanciar os símbolos sociais, como o cinema, de suas propostas de formação docente criando, assim, lacunas no exercício da docência.

E, no sentido de compreender a importância do cinema na formação docente, a pesquisa retratada nesse artigo teve por objetivo descobrir se as produções cinematográficas têm, realmente, influência na prática educativa dos futuros docentes e quais as contribuições que esse tipo de mídia acrescenta na formação de professores. A importância desse 
estudo está na possibilidade de análise da inserção do cinema na formação de professores no Estado de Sergipe possibilitando, assim, adequar as necessidades regionais às características didáticas dessa proposta midiática. E, para tal procedimento, utilizaram-se como sujeitos de pesquisa os alunos do último período das Licenciaturas de dois campus da Universidade Tiradentes (UNIT), sendo eles Campus I - Centro, com as licenciaturas em Letras-Português, Letras-Inglês, Geografia e História, e Campus II - Farolândia, com as licenciaturas em Matemática, Informática e Educação Física.

\section{RELACÕES SOCIAIS, COMUNICAÇ̃̃̃, CINEMA E EDUCAÇ̃̃O: UMA RELAÇ̃̃O NECESSÁRIA?}

As relações sociais ocorrem através da interação recíproca com o outro, mediadas pelo processo de comunicação, seja ele escrito, visual ou auditivo, onde é necessário estarem presentes o emissor, a mensagem e o receptor. 0 homem por si é um ser social e, portanto, necessita se comunicar, se expressar e se fazer ouvir. Para tanto, se utiliza de sistemas de signos, tais como a escrita, o som e a imagem, que auxiliam nesse processo.

Os motivos que levam o ser humano a se comunicar estão pautados nas questões de compartilhar, seduzir e convencer. Compartilhar a partir do sentido que os homens necessitam trocar informações, pois é a através da mensagem que ocorre a transmissão de sentidos e sentimentos. Seduzir, pois a partir da mensagem é possível determinar a vontade do outro. E, por fim a convicção, ou seja, Convencero outro que a informação transmitida é verdadeira e necessária.

Esses três fatores estão relacionados com Teoria da Comunicação, analisada com propriedade por Wolton (2010, p. 19):

Primeiro: a comunicação é inerente à condição humana. Não há vida pessoal e coletiva sem vontade de falar, de comunicar, de trocar, tanto na escala individual quanto coletiva. Segundo: os seres humanos desejam se comunicar por três razões: compartilhar, convencer e seduzir. Com frequência simultaneamente por essas três razões, mesmo se isso nem sem- pre é enunciado. Terceiro: a comunicação esbarra na incomunicação. 0 receptor não está sintonizado ou discorda. Quarto: abre-se uma fase de negociação na qual os protagonistas, de modo mais ou menos livre e igualitário, tentam chegar a um acordo. Cinco: chama-se de convivência, com suas fragilidades e pontos fortes, o resultado positivo dessa negociação. A negociação e a convivência são procedimentos para evitar a incomunicação e as suas consequências, frequentemente belicosas.

A partir dessas condições, situamos o cinema como elemento importante no processo comunicacional do ser, pois reúne a imagem e o som como signos da transmissão da informação, gerando, assim, “espectadores multimídia, que se relacionam com o cinema de diversas maneiras em salas, na televisão, no vídeo e revistas de espetáculos, percebendo-o como parte de um sistema amplo e diversificado" (CANCLINI, 1995, p. 177).

Há muitas discussões sobre o exato período de criação do cinema enquanto manifestação comunicacional da sociedade. Contudo, se utiliza como marco histórico a data de 28 de dezembro de 1895, quando os irmãos Lumière exibiram no Grand Salão de Paris, a primeira projeção cinematográfica a partir da tecnologia denominada cinematógrafo.

Inicialmente, as projeções eram apenas de imagens, pois havia problemas técnicos de sincronia dos diálogos. 0 período em que ocorreu esse descompasso ficou conhecido como era do cinema mudo e foi re- 
presentado pelo expoente Charlie Chaplin. Em 1927, os estúdios Warner Bros lançaram o filme The Jazz Single, um musical que entrou para história como a primeira projeção a sincronizar as falas e as cantorias.

A era áurea do cinema ocorreu entre os anos 20 e 50 do século $X X$, quando revelou inúmeros nomes e produções que marcaram períodos históricos. Contudo, a partir da década de 60, começou ocorrer o declínio do cinema, principalmente, da indústria norte-americana. Apesar desse enfraquecimento, inúmeras produções cinematográficas marcaram as décadas posteriores, entre elas, os filmes O Poderoso Chefão (1972), de Francis Fred Coppola, e Laranja Mecânica (1971) de Stanley Kubrick nos anos 70 . Já os anos 80 se caracterizaram pela produtividade do cinema estadunidense. Martin Scorsese dirigiu a produção Touro indomável (1980) e Robin Williams interpretou o professor John Keating em Sociedade dos Poetas Mortos (1989), educador que propiciou o grito de liberdade à juventude, a partir da expressão Carpe Diem ${ }^{1}$.

Nos anos 1990 imperou a diversidade nas produções, onde é permitido inovar e misturar. Os filmes Silêncios do Inocentes (1991), de Jonathan Demme, e Pulp Fiction (1994), de Quentin Tarantino, marcaram toda uma geração. A partir dos anos 2000, a indústria cinematográfica sofreu uma grande mudança que fortaleceu o cinema hollywoodiano, devido às modificações no formato das projeções, tornando-as megaproduções que arrebatam milhares aos cinemas. Isso foi possível graças às novas tecnologias, que possibilitaram inclusive a criação do cinema em terceira dimensão.

A partir do momento de criação do cinema, no final do século XIX, até as projeções em dimensões antes impossíveis, muitos fatos ocorreram. Contudo, o objetivo do cinema de informar, divertir e sensibilizar não sofreu alterações. É a partir desse contexto que surge a importância dos filmes na educação, pois, como nos descreve Linhares (2007, p. 37):

1 Tradução Nossa: “Aproveite o Dia”
$\mathrm{Na}$ construção dos alicerces teóricos desse novo campo à educação considerar os processos culturais, constituídos e constituidores da ação comunicativa e de aprendizagem e que suas diversas formas de manifestação enriqueçam a ação pedagógica. Não se educa sem comunicar; por isso, a inter-relação comunicação/ educação contribui em diversas frentes para que o espaço escolar possa efetivamente tornar-se um espaço sócio histórico de participação política e cidadão.

Para que seja possível essa transformação, é necessário que a escola reconheça na comunicação um campo propicio à negociação de sentidos e que, em seus suportes tecnológicos e diferentes linguagens, encontre os elementos constitutivos do processo de aprendizagem da sociedade contemporânea e que encare os meios de comunicação social e, em especial, aqueles que trabalham com a linguagem audiovisual como parceiros nessa caminhada dinâmica de transformação de sua prática pedagógica (LINHARES, 2007).

O professor é o responsável pela mediação do processo educativo, pois busca elementos que auxiliem a sua prática educativa com o objetivo de que seus alunos internalizem os conhecimentos trabalhados em sala de aula (FREIRE, 2006). E o cinema é um elemento que possui essas características, porque, ao unir as imagens, os movimentos e os sons, oportuniza primeiro prender a atenção do aluno-espectador e, segundo, se elaborado de forma clara, consegue transmitir mensagens que provocam questionamentos e posicionamentos àqueles que fazem seu uso.

A procura por novas formas de educar sempre esteve presente no processo educativo. Desde a criação do cinema no final do século XIX, presenciamos a intenção de utilizar os filmes como elemento pedagógico.

Desde a década de 1910, os anarquistas desenvolveram uma intensa reflexão sobre os usos do cinema como um instrumento a serviço da educação do homem do povo e da transformação social (1), deven- 
do este se converter em arte revolucionária. 0 pensamento católico também se dedicou à questão do cinema educativo, preocupado com a questão moral dos filmes exibidos. A Igreja criou os Cineacs, salas de cinema nas paróquias e associações católicas, que tinham por objetivo apreciar os filmes segundo as normas traçadas pela Igreja (2). Os educadores, por sua vez, combatiam o que eles chamavam de "cinema mercantil" e propunham a criação do cinema educativo, que, segundo eles, poderia trazer benefícios pedagógicos aos alunos ao mostrar de forma mais real diversos aspectos da natureza e da geografia do Brasil. Para estes, o cinema educativo representava a luta contra o cinema "deseducador" e "portador de elementos nocivos e desagregadores da nacionalidade (3)" (CATELLI, 2003, p. 1).

A transposição didática das grandes produções cinematográficas para o espaço da educação básica ocorreu a partir das modificações ou miniaturização das tecnologias de reprodução, em que os projetores das salas de cinemas eram levados ao espaço escolar. Contudo, a partir da invenção do videocassete, em 1971, esse processo sofreu uma massificação e o cinema alcançou novos espaços educativos, sempre atrelados ao videocassete e, posteriormente, ao DVD.

A importância da utilização de filmes no contexto educativo acaba refletindo na formação dos professores uma vez que os docentes necessitam adequar-se à ótica do filme como elemento comunicacional e pedagógico no ensino. Assim, o valor das produções cinematográficas para a formação docente está presente na sensibilização do professor em temáticas que se fazem presentes no contexto educativo.

O valor desses filmes em transmitir e provocar debates está presente em algumas produções cinematográficas tais como, Ao Mestre com carinho (To Sir, with Love, 1967), Sociedade dos poetas mortos (Dead Poets Society, 1989), Escola da Vida (School of Life, 2005) e o documentário brasileiro Pro Dia Nascer Feliz (2007).
Ao Mestre com Carinho (To Sir, with Love, 1967), filme dirigido por James Clavell, realiza análise de um ambiente escolar da década de 60 . No entanto, se transpusermos seus elementos, poderão ser vistos com facilidade na contemporaneidade. A produção retrata a luta diária de um professor negro, engenheiro de formação, em uma escola do subúrbio londrino. Acostumado com as adversidades, o professor Mark Thackeray se faz presente em uma luta diária no sentido propiciar aos seus alunos uma formação que possibilite a sua inserção em uma sociedade cada vez mais exigente.

A produção cinematográfica Sociedade dos Poetas Mortos (Dead Poets Society, 1989) é uma proposta por um grito de liberdade da juventude em contraponto aos valores sociais impostos em escola de regime fechado. Na produção, Robin Willians interpreta John Keating, um docente flexível de uma instituição de ensino onde os valores de tradição, disciplina, honra e excelência são preconizados aos seus alunos. Contudo, Keating propõe uma mudança nessa postura ao tentar internalizar nos discentes a busca pelas suas paixões pessoais a partir da ideia de "livres pensadores", pautada na proposta filosófica do Carpe Diem. Ao transpormos a proposta do filme para educação atual, é possível visualizar elementos latentes tais como: a inflexibilidade dos currículos; a postura docente tradicional, na qual o professor se considera o detentor do saber e os alunos "repositórios" de conhecimento; e a busca desenfreada por uma excelência desmedida, voltada para a lógica econômica, em contraponto à formação social cidadã do aluno.

Já no filme Escola da Vida (School of Life, 2005), o ponto de analise é a postura docente a partir da crítica a educação tradicional centrada nas "grades" fechadas, disciplinas estanques e metodologias descompassadas com o perfil e a realidade do aluno. A crítica a esses elementos presentes na educação começa a ser desconstruída após a chegada de um jovem professore ex-aluno da Escola Fallbrook Middle School, que, a partir de uma prática educativa inovadora, modifica as relações escolares, principalmente entre docentes e dis- 
centes, o que acaba gerando alguns desconfortos com os outros professores. Porém, com o passar do tempo, aqueles docentes de postura tradicional começam a visualizar que, talvez, os alunos na contemporaneidade exijam uma nova maneira de educar.

Por fim, o documentário brasileiro Pro Dia Nascer Feliz (2007) demonstra as realidades educativas bra- sileiras dentro da ótica do público e do privado. Ele aborda a questão de como os jovens veem a escola e como eles se relacionam com esse espaço. Essa abordagem é vista por depoimentos de estudantes de escolas do Rio de Janeiro, São Paulo e Pernambuco. A partir das perspectivas abordadas, é possível visualizar sonhos similares, mundos distintos e possibilidades diferenciadas.

\section{PROCEDIMENTOS METODOLÓGICOS}

O artigo em questão apresenta considerações finais da pesquisa intitulada "Filmes sobre Professor: análise da utilização e contribuição para identidade de professores sergipanos em formação", elaborada no Grupo de Estudos Comunicação, Educação e Sociedades (GEGES/CNPQ), com o apoio financeiro da Fundação de Apoio à Pesquisa e Inovação Tecnológica do Estado de Sergipe (FAPITEC-SE), cujo objetivo foi compreender qual a influência do cinema, através de filmes sobre professores, na formação do futuro docente, tal pesquisa é caracterizada como social descritiva, pois “aborda [...] a descrição, registro, análise e interpretação de fenômenos atuais [...] visa melhorar a compreensão de ordem, de grupos, de instituições sociais e éticas" (MARCONI; LAKATOS, 2006, p. 20-21).

Tal projeto de pesquisa foi desenvolvido em duas de etapas. A primeira compreendeu a aplicação de questionários aos docentes das licenciaturas da UNIT e a segunda envolveu a aplicação de questionários aos alunos matriculados nessas licenciaturas. 0 ob- jeto de reflexão desse artigo são os sujeitos presentes na segunda etapa, ou seja, os licenciandos, uma vez que os docentes das disciplinas em questão já foram analisados em trabalhos anteriores (LINHARES, 2010; CUNHA, et.al, 2010).

Dessa forma, o processo de desenvolvimento da segunda etapa ocorreu a partir do contato inicial com os coordenadores das licenciaturas, com o intuito de obtenção de autorização para aplicação dos questionários junto aos licenciandos. Uma vez autorizados, os pesquisadores foram às respectivas salas de aulas, onde explicaram os objetivos do projeto, a forma de análise dos dados e a importância da questão do anonimato dos sujeitos da pesquisa aos licenciados que participaram do estudo. Após isso, foram aplicados os questionários aos discentes presentes naquele momento em sala de aula. Após o término do prazo para resposta do instrumento, cerca de 20 minutos, o mesmo foi recolhido para a tabulação e análises posteriores.

\section{DOCÊNCIAECINEMA: UM OLHAR SOBREOSDADOS}

O panorama das licenciaturas no país pode ser analisado a partir dos dados do Censo da Educação Superior de 2009, que revelou um considerável aumento no

número de matriculados nas licenciaturas no país, saltando de 648.666 em 1997 alunos matriculados para 1.191.763 alunos matriculados em 2009 (MEC, 2009). 
Esses dados demonstram um aumento considerável pelo exercício da docência. Uma parcela desses futuros licenciandos irá atuar no Estado de Sergipe, onde a pesquisa se desenvolveu, e irão encontrar matriculados no ensino regular 436.805 alunos nas redes públicas de ensino municipal e estadual (MEC, 2011). A partir desses dados, é possível visualizar a importância da UNIT no processo de formação de professores que irão atuar em práticas educativas junto a esses discentes. Assim, a pesquisa torna-se relevante, pois analisa um dos pilares da educação de qualidade, que é a questão da formação docente, voltando-se em especial para inserção das mídias, como o cinema, no processo de capacitação desses futuros professores.

Através dos dados obtidos a partir dos questionários respondidos, é possível elaborar o perfil do futuro professor, no caso sujeito participante da pesquisa na UNIT. Ele é em, sua maioria do sexo feminino (49\%), assim, seguindo uma tendência nacional revelada no Censo da Educação Superior de 2009, que demonstrou que $55,1 \%$ dos alunos matriculados nas gradu- ações presenciais são do sexo feminino (MEC, 2009). Podemos atribuir esse fator à ótica de que a docência ainda é discursada como uma profissão "feminizada", acarretando o distanciamento de homens das salas de aulas, isso porque, como nos demonstra Ferraz (2006), “[...] quando pensamos na docência, os olhos e fala de nosso pensamento se inclinam a associá-la à imagem feminina, sobretudo quando o alvo é o exercício dessa profissão em salas de aula [...]".

O licenciando da UNIT possui idade entre 18 e 25 anos (61\%), ou seja, desmistificando aquela ideia que a licenciatura não atrai os mais jovens. De acordo com dados do Censo do Professor de 2007, o Brasil contava naquele período com 114.364 docentes com idade até 24 anos. Esse dado demonstra um número considerável de jovens que estão procurando a carreira docente e isso pode ser atribuído, entre outros fatores, à questão da estabilidade no exercício da função em órgãos públicos e o fato de a licenciatura ser uma graduação, normalmente, de custo mensal baixo e de rápida inserção no mercado de trabalho (Ver Quadro 1).

Quadro 1 - Faixa Etária

\begin{tabular}{lcc}
\hline Idade & Quantidade & Percentagem (130 alunos) \\
\hline 18 a 25 & 80 & $61 \%$ \\
26 a 30 & 28 & $21 \%$ \\
31 a 35 & 14 & $11 \%$ \\
36 ou mais & 7 & $5 \%$ \\
Não responderam & 1 & $1 \%$ \\
\hline TOTAL & $\mathbf{1 3 0}$ & $\mathbf{1 0 0 \%}$ \\
\hline
\end{tabular}

Em contraponto, a análise dos dados do Quadro 1, no que concerne à faixa etária, aponta que pessoas de 36 anos ou mais não procuram tanto à licenciatura da
UNIT, apenas (5\%). Dessa maneira, há crescimento de educadores jovens no Estado de Sergipe, tendo em vista que esses licenciandos serão os futuros professores. 
No tocante à questão dos filmes que tratam a formação de professores, $75 \%$ dos alunos responderam que assistiram a produções que tratam dessa temática, $22 \%$ não assistiram e $2 \%$ não responderam. As disciplinas de Didática e Filosofia e Cidadania foram as que mais reproduziram filmes em suas aulas.

[...] a Didática se caracteriza como mediação entre as bases teórico - cientificas da educação escolar e a prática docente. Ela opera como uma ponte entre o "o quê" e "como" do processo pedagógico escolar [...] A Didática descreve e explica nexos, relações e ligações entre o ensino e a aprendizagem; investiga os fatores co-determinantes desses processos; indica princípios, condições e meios de direção do ensino, tendo em vista a aprendizagem, que são comuns ao ensino das diferentes disciplinas de conteúdos específicos (LIBÂNEO, 1994, p. 28).

A partir disso, a utilização do cinema por parte da disciplina Didática ocorre devido ao fato de ela estar relacionada com a prática de ensino, assim reforçando a ideia do poder educativo do cinema.

Com relação às produções mais vistas, estão a Escola da Vida e Vem Dançar (16,9\%), Mentes Perigosas e Ao Mestre com Carinho (16,1\%). No entanto, as menos visualizadas foram $O$ nome da Rosa, Dança Comigo, Clube de Cinco (0,7\%). Os filmes Escola da Vida, Mentes Perigosas, Ao Mestre com Carinho são ambientados em escolas e têm, na figura do professor, o personagem principal, eixo desencadeador do roteiro, que tem nas dificuldades que esses educadores têm para lidar com os alunos que, invariavelmente, são problemáticos, que é o principal elemento de discussão. Nestes filmes, é recorrente questão do "salvar" os alunos, em sua maioria desacreditados e marginalizados, por meio da educação.

Percebe-se uma semelhança no enredo destes filmes, tomando como exemplo o filme Ao Mestre Com Carinho, que se passa nos anos 1960, que os alunos são retratados como incertos (da mesma maneira que nos demais filmes ambientados em décadas posteriores) uma espécie de fôrma, que vai se transformar em um clichê. Tendo em conta um idealismo pueril e pouco político do professor, que é tido como um salvador e herói, e a preocupação quanto a este tipo de professor construído pelo filme, as discussões alimentadas pelo professor formador em sala vão no sentido de averiguar o que os futuros professores apreendem sobre o papel do professor a partir destes filmes. Classificado entre os mais utilizados em sala de aula, o filme Vem Dançar aborda outro enfoque e atenta para o papel do grupo e do professor na construção deste contexto.

A partir disso, podemos observar que a relação aluno-cinema-graduação é constante. Contudo, precisamos analisar de que forma esses discentes encaram a importância dos filmes em suas práticas educativas. Desse modo, 36,1\% dos alunos responderam que o maior benefício do cinema, em contrapartida com outras linguagens (livros, revistas, musicas, pinturas etc.), é a vivência de sentimentos e a possibilidade de sentir emoções. Isso indica que os futuros educadores enxergam no cinema a possibilidade de chegar até o aluno, através de filmes, com apelo sentimental.

A pergunta que fica é se não há nada mais a ser enxergado e extraído dos filmes. Algo comum no cinema, especificamente no cinema hollywoodiano, é a utilização exacerbada do apelo sentimental. Uma gama de cenas capazes de sensibilizar as pessoas, apelo utilizado a fim de prender atenção dos que assistem, e deixando à margem ou não dando devido valor a outros pontos, como a preocupação com a linguagem. Ao longo da evolução cinematográfica, evolução tecnológica, tornou-se possível segurar o público com imagens chocantes, grandes efeitos. Foi observado nessa pesquisa que os alunos não se sentem e não são estimulados a dar o devido valor proporcionado pela linguagem.

Outro benefício de destaque nos questionários foi a objetividade do filme, o que mostra o interesse por uma produção que seja clara e concisa, dado a necessidade contemporânea de não se perder tempo, ir ao 
ponto sem rodeios. No entanto, ao analisar o quadro 2, demonstrado abaixo, fica claro que os alunos não tem interesse no cinema pela possibilidade de alcance de conhecimento por meio da linguagem. Isso leva a crer que, até mesmo os professores, não voltam o olhar ou o ouvido, para análise desse item rico que é a construção de um discurso a partir de uma linguagem audiovisual que reúne a oralidade e a imagem, para um exercício de ver que vai muito além do texto escrito.
Mas, se os futuros educadores não consideram a linguagem cinematográfica de maneira profunda, a linguagem que é a ferramenta com a qual tanto se consolida a educação, e que, segundo as falas dos professores e alunos, faz a diferença pela qual o cinema é escolhido por estes professores, por que uso do cinema na educação? Ele está sendo aproveitado da melhor maneira ou é usado como um conjunto de imagens que reproduzem a realidade?

Quadro 2 - Benefícios

\begin{tabular}{lc}
\hline Benefícios & Quantidade \\
\hline Abordagem visual & 44 \\
Conduz os alunos ao consenso & 22 \\
História com começo meio e fim & 11 \\
Proximidade com o cotidiano & 38 \\
Resumo de obras literárias & 9 \\
Sonoridade & 9 \\
Identificação de ideologias entre classes & 17 \\
Linguagem mais acessível & 40 \\
Objetividade & 30 \\
Percepção da realidade & 44 \\
União entre som e imagem & 32 \\
Vivência de sentimentos e emoções & 47 \\
\hline
\end{tabular}

Ao observamos o Quadro 3 abaixo, é possível estabelecer critérios para a exibição de filmes na formação de professores, pois, $58,4 \%$ responderam que a projeção cinematográfica necessita trazer aspectos que auxiliem na formação docente, tais como a capacidade de mobilizar discussão $(46,15 \%)$, mensagem do filme $(46,1 \%)$, relação filme/conteúdo programático $(30,7 \%)$. Nesse quesi- to, percebe-se uma diferença tênue entre os itens, validando a importância e a capacidade de obter, por meio dos filmes, auxilio na formação do profissional, a possibilidade de, a partir das histórias retratadas, surgir debates, interação, opiniões, percepções além de, evidentemente, deixar claro que a disposição, o interesse no filme, depende do tema e do conteúdo abordado. 


\section{Quantidade}

$\begin{array}{lc}\text { Auxílio na formação } & 76 \\ \text { Capacidade de mobilizar discussão } & 60 \\ \text { Qualidade da produção cinematográfica } & 11 \\ \text { Conteúdo / tema do filme } & 30 \\ \text { Contexto cinematográfico } & 9 \\ \text { Mensagem do filme } & 54 \\ \text { Relação filme / conteúdo programático } & 40 \\ \text { Relação filme/contexto social } & 49\end{array}$

Ao analisar a prática de seus professores ao proporem a utilização de filmes em sua formação, os licenciandos descrevem que os objetivos a serem atingidos foram despertar a reflexão sobre a prática educativa $(53,8 \%)$, propiciar novas habilidades ao docente $(48,4 \%)$ e discutir a relação professor/aluno. Fica evidente, por meio dos dados do Quadro 03, a credibilidade atribuída ao cinema no que diz respeito à educação. Os que serão futuros professores deixam claro a capacidade e o alcance do cinema na prática educativa, concordando que, por meio dos filmes, é possível refletir sobre o modo como a educação está sendo praticada e de que maneira é possível ser criadas novas maneiras docentes.

\section{CONSIDERAÇ̃̃ES FINAIS}

Vivemos em um contexto social no qual os avanços das tecnologias ocorrem com rapidez, possibilitando novas maneiras de realização, transmissão e absorção de conteúdo intelectual. $E$, ao aproveitar-se dessas características, o cinema exerce de extrema valia para educação, pois permite mesclar as linguagens próprias de sua arte com as possibilidades pedagógicas que os diálogos, mensagens e objetivos presentes nos filmes trazem. Por isso, é inadmissível fechar os olhos para a realidade: o cinema não é distração. Não apenas. Mas, sim, uma arte a serviço da sociabilidade e educação. Também é preciso dar-se o devido valor às ferramen- tas capazes de auxiliar o aprendizado. Não adianta fugir da modernidade, assim como não se deve utilizar o cinema como "tapa-buraco", ou seja, como uma mídia paliativa. A cinematografia necessita ser enxergada como uma grande aliada às escolas, aos estudantes, aos mestres. 0 estudo realizado nesse projeto mostra o poder transformador do cinema diante dos futuros educadores, que serão responsáveis pela formação da sociedade. A partir dos dados coletados junto aos sujeitos da pesquisa, foi possível traçar um panorama situacional sobre a questão do uso de filmes na formação de professores. 
A partir disso, é possível constatar que os docentes precisam planejar a utilização do cinema em sala de aula, preparar-se para oferecer ao aluno aula qualidade, dar suporte suficiente que possibilite o aluno aprender e apreender o melhor possivel dos filmes assistidos. $\mathrm{E}$ isso pode ocorrer a partir de ações integradas dos docentes, buscando selecionar, estudar e aprofundar-se em projeções cinematográficas que levem o licenciado a observar seu papel enquanto docente em formação e sua atuação em sala de aula. E, invariavelmente, será possível se o mestre tiver em mente a resposta para a seguinte pergunta: "Por que estou utilizando esse filme?” Não adianta nada assistir a filmes se não houver uma razão, um motivo cabível e de valor para a turma. 0 que os alunos podem reter ao assistir a determinado filme é o que faz coerente a utilização da sétima arte. É preciso saber escolher um filme adequado para chegar aonde deseja e não utilizá-lo como recreação.

\section{REFERÊNCIAS}

CANCLINI, Nestor. Consumidores e cidadãos: conflitos multiculturais da globalização. Rio de Janeiro: Ed. UFRJ, 1995.

CATELLI, Rosan Elisa. Cinema e Educação em John Grierson. Revista Menemocine, v. 1, p. 1-3, 2003. Disponivel em <http//:www.mnemocine.com.br>.Acesso: 15 de set. de 2011.

CUNHA, Laise S.C. ; MOURA, Lindsey F.P. ; LINHARES, R. N. . Filmes sobre professores na formação docente. In: IV Colóquio Internacional Educação e Contemporaneidade. Aracaju : Editora da UFS, 2010. v. 1. p. 1-13.

FERRAZ, R. C. Gênero, masculinidade e docência: visões dos alunos de pedagogia. In: Seminário internacional fazendo gênero 7 - gênero e preconceitos, 2006, Santa Catarina. Anais do seminário internacional fazendo gênero 7 - gênero e preconceitos,
Logo, o estudo dos dados e a análise dos itens possibilitaram ampliar a percepção sobre o uso e a importância do cinema em sala principalmente se usado a fim de conscientização para os futuros licenciados, sem, no entanto, desconsiderar sua constituição enquanto linguagem, produto cultural, econômico e político, embora fique claro que, muitas vezes, não é utilizado de maneira mais profunda, limitando-se ao raso, ao assistir e se comover, a serviço de mostrar o quanto o professor é capaz de modificar a vida de um aluno. Comprova-se, entretanto, que o cinema precisa ser visto como algo a mais que simples paliativo ou acréscimo e sim como suporte, ferramenta a mobilizar grandes questionamentos e reflexões. É preciso sair um pouco do patamar emotivo, passar a usufruir de maneira mais consistente o leque de possibilidades ofertadas pelo cinema no que diz respeito ao meio educacional.

2006. Disponível em: <www.fazendogenero7.ufsc. br/artigos/R/Raimundo_Cassiano_Ferraz_23.pdf>. Acesso: 17 ago. 2011.

FREIRE, Paulo. Pedagogia da autonomia: saberes necessários à prática educativa. São Paulo: Paz e Terra, 1996.

LINHARES, Ronaldo Nunes. Reflexões: Filmes Sobre Professores Na Formação Docente. In: I Seminário Internacional: Contributos da Psicologia em Contextos Educativos. Braga: Instituto de Educação - Universidade do Minho, 2010. v. 1. p. 1-12.

LINHARES, Ronaldo Nunes. Gestão em comunicação e educação: 0 audiovisual no espaço escolar. Alagoas: EDUFAL, 2007.

MARCONI, Marina de Andrade; LAKATOS, Eva Maria. 
Técnicas de pesquisa: planejamento e execução de pesquisa, amostragens e técnicas de pesquisa, elaboração, análise e interpretação de dados. 6 . ed. São Paulo: Atlas, 2006.

MEC. Censo da Educação Superior de 2009. Brasília: MEC. 2009. Disponível em <www.inep. gov.br>. Acesso: 15 ago. 2011.
MEC. Censo da Educação Básica 2010. Brasília: MEC. 2011. Disponível em <www.inep. gov.br>. Acesso em 15 de ago. 2011.

WOLTON, Dominique. Informar não é comunicar. Porto Alegre: Sulina, 2010.

\begin{abstract}
1 BOLSISTA PROCAPS/UNIT/FAPITEC. Mestrando em Educação (UNIT) Graduado em Pedagogia (UNIABC). Programa de Pós-Graduação em Educação da Universidade Tiradentes (PPED-UNIT). Aracaju, Sergipe. E-mail: albano.goes@hotmail.com.

2 BOLSISTA/UNIT/FAPITEC. Graduando em Comunicação Social: Jornalismo da Universidade Tiradentes (UNIT), Aracaju, Sergipe. E-mail: edsonvictor@hotmail.com.

3 Doutor em Ciências da Comunicação (ECA/USP), Mestrado em Educação (UFS), Graduado em História (UFS). Docente do Programa de Pós-Graduação em Educação da Universidade Tiradentes (PPED-UNIT). Aracaju, Sergipe.E-mail: ronaldo_linhares@unit.br.

